\title{
PAISAJES DEL GAUCHITO GIL EN BUENOS AIRES ¿NEOCULTURAS URBANAS DE FE?
}

\author{
PAISAGENS DE GAUCHITO GIL EM BUENOS AIRES. \\ NEOCULTURAS URBANAS DA FÉ?
}

\section{- CRISTINA TERESA CARBALLO ${ }^{1}$}

1 Doctora en Geografía Social (2008) por la Université Du Maine, Francia; con mención de honor. Y, obtuvo el Pos Doctorado en Ciencias Sociales (2015) por la Universidad Nacional de Córdoba. En la actualidad es la directora de la Licenciatura en Geografía (CCC) 2016-2020 en el Departamento de Ciencias Sociales. Doutora em Geografia Social (2008) pela Université Du Maine, França; com menção de honra. E obteve o pós-doutorado em ciências sociais (2015) pela Universidade Nacional de Córdoba. Atualmente, é diretora do Bacharelado em Geografia (CCC) 2016-2020 no Departamento de Ciências Sociais. E-mail: cristina.carballo@unq.edu.ar

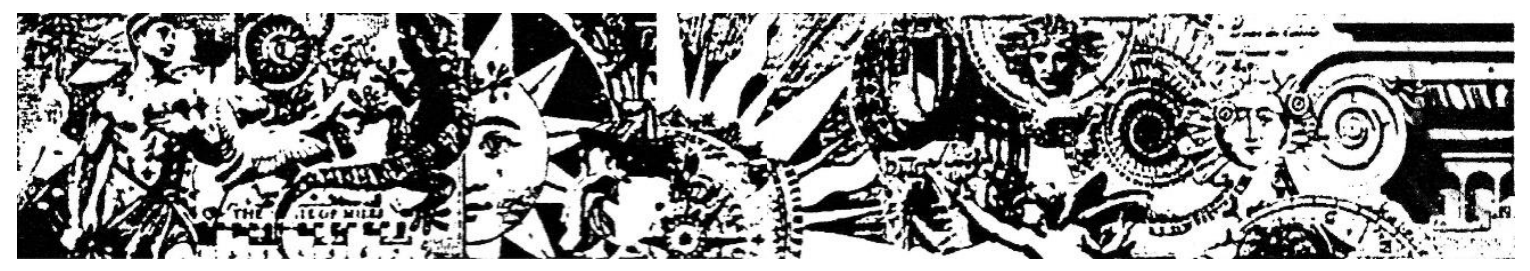

Resumen: El Gauchito conforma una religiosidad popular no regulada, mágica y con matrices de devoción católica. En su creencia y fe se encarna lo masculino con la rebeldía y la búsqueda de justicia. Una presencia que reacciona frente al poder que oprime a los más vulnerables. Acaso estemos en presencia de procesos urbanos neoculturales de fe. En esas primeras observaciones surgieron preguntas: ¿Por qué llega el santuario popular del Gauchito Gil a la ciudad? ¿Qué imaginarios convoca y cómo se agencia el contacto con lo sagrado? ¿El origen de ese gaucho qué raíces tiene y qué voces populares resuenan? En este diálogo urbano de imaginarios sagrados y comunidad: ¿cómo trasciende en el territorio? Estos interrogantes permitieron organizar las ideas del trabajo en tres momentos: en el primero se echa mano a la descripción y a la evidencia del santuario del Gauchito Gil en la ciudad, retomando el papel de la ciudad como un lugar de encuentro histórico entre lo divino y lo humano. En un segundo momento, se realiza un contexto histórico para entender los simbolismos y su transmisión oral de los fieles sobre este origen pasado y milagroso. En una tercera etapa, nos introducimos en formas culturales de interacción social de la religiosidad que requieren de una solidaridad colectiva y milagrosa frente a la ciudad postsocial. Así, el santuario se lo define como una proyección territorial de los imaginarios sagrados. Y finalmente, una síntesis de ideas fuerza que nos posicionan en un lugar de comprensión neocultural del santuario, objeto de esperanzas y sueños.

Palabras claves: Gauchito Gil, religiosidad popular, neoculturas urbanas, Buenos Aires. 


\section{PAISAGENS DE GAUCHITO GIL EM BUENOS AIRES. NEOCULTURAS URBANAS DA FÉ?}

Resumo: O Gauchito forma uma religiosidade popular não regulada, mágica e com matrizes de devoção católica. Em sua crença e fé, o masculino se encarna com a rebeldia e a busca da justiça. Uma presença que reage ao poder que oprime os mais vulneráveis. Uma presença que reage ao poder que oprime os mais vulneráveis. Caso estejamos na presença de processos urbanos neoculturais de fé. Nessas primeiras observações, surgiram questões: Por que o santuário popular de Gauchito Gil chega à cidade? Quem imaginário convoca e como é realizada o contato com o sagrado? A origem daquele gaucho, quais são suas raízes e quais vozes populares ressoam? Neste diálogo urbano de imagiários sagrados e comunidade, como ocorre essa trasncendência no território? Essas questões nos permitiram organizar as idéias de trabalho em três momentos: na primeira, a descrição e a evidência do santuário Gauchito Gil na cidade foram retomadas, assumindo o papel de cidade como ponto de encontro histórico entre o divino e o humano. Em um segundo momento, realizaremos um levantemaneto sobre o contexto histórico para compreender o simbolismo e sua transmissão oral dos fiéis sobre essa origem milagrosa e passada. E numa terceira etapa, nos apresentamos em formas culturais de interação social da religiosidade que exigem uma solidariedade coletiva e milagrosa com a cidade pós-social. Assim, o santuário é definido como uma projeção territorial de imaginários sagrados. E finalmente, uma síntese de idéias fortes que nos posicionam em um lugar de compreensão neocultural do santuário, objeto de esperanças e sonhos.

Palavras-chave: Gauchito Gil, religiosidade popular, neoculturas urbanas, Buenos Aires.

\section{LANDSCAPES OF THE GAUCHITO GIL IN BUENOS AIRES. NEW URBAN CULTURES OF DEEP RELIGIOUS BELIEF?}

Abstract: The Gauchito represents a certain kind of popular religiosity that has no rules, it is magical and shaped by the matrix of Catholic piety. Manliness is embodied in its strong-held beliefs and faith because of its acts of rebellion and its quest for justice. It is an existence that defies the Power that oppresses the most vulnerable and marginalized people. We might be witnessing the growth of new urban cultures of deep religious belief. When conducting the observation work, quite a number of questions arose, such as the following: How come that the popular shrine of the Gauchito Gil ends up in a city? What imaginary constructs does it summon up and how does it get hold of what sacredness is? Where does this gaucho come from? What can be said about his roots and what are the popular voices that are echoed in him? In this urban dialogue between sacred imaginary constructs and community, how is it that the Gauchito goes beyond borders? Thus, all the previous issues became the guidelines of the present work which has been organized along three stages: the first one refers to the Gauchito Gil's shrine in itself, describing it and providing evidence of its urban location and the role of the city as the context of a historic encounter between the divine and the human. Secondly, the historical context is referred to in order to understand the religious symbols and the transmission of its miraculous background by word of mouth of the believers. And the third stage introduces the topic of the cultural representations of social interaction that piety adopts and their requirements for a collective and miraculous solidarity in order to face the post social city. Thus, the shrine is defined as a territorial projection of sacred imaginary constructs. And lastly, a summary of the key ideas that put in perspective our understanding of the new culture the shrine represents as an object recipient of hopes and dreams.

Key words: Gauchito Gil, popular religiosity, new urban cultures, Buenos Aires. 


\title{
Introducción: La llegada del Gauchito Gil a la ciudad de Buenos Aires
}

\begin{abstract}
"No faltan especialistas en estudios culturales que también intentan simplificar ese desorden buscando en una posición subordinada (la subalternidad, la condición poscolonial o algún discurso minoritario) el observatorio alternativo que dará la clave para ya no tener que asombrarse de lo que resulta difícil entender. (...) Aparece, entonces, como indispensable la tarea cultural: repensar los significados, el sentido moderno, aceptando la complejidad de las interacciones globales. Rediscutir la autonomía de los campos culturales, políticos, económicos, y sus necesarias interconexiones" (García Canclini, 2005, p. 69-70)
\end{abstract}

El paisaje se inscribe, siempre, en una tensión constitutiva entre su apropiación como signo, que le otorga el control, modo, y forma de representación social sobre un determinado objeto de la realidad (Carballo, 2018).

Podríamos agregar que el paisaje nos provoca a re-pensar nuestras realidades espirituales. Hace unos pocos años un paisaje urbano asombraba mis ojos: sobre la avenida Corrientes crecía un santuario del Gauchito Gil en clara competencia o solidaridad religiosa, vaya uno a saber, con la imagen de la Virgen de Luján. La expresión de estos símbolos de religiosidad territorial era contundente, a la vez de extraños e invasores a la vida urbana de Buenos Aires.

Figura 1 - Plaza los Andes²

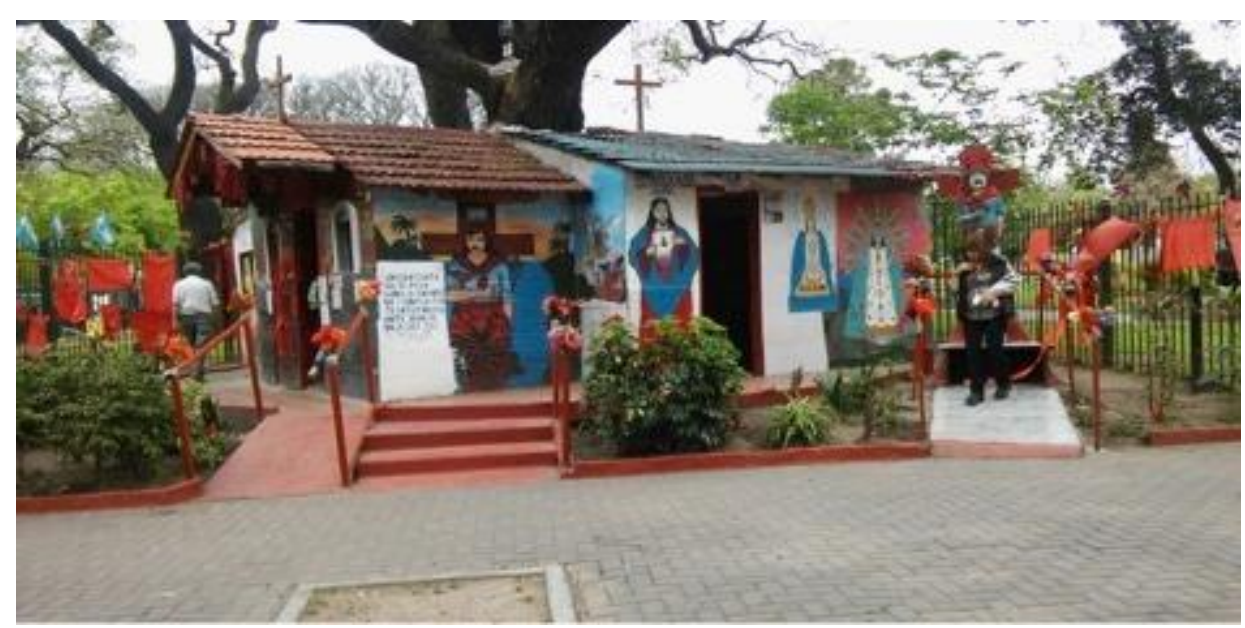

Fuente: Carballo, 2016.

Como sabemos, cualquier tipo de localización en el espacio es en sí misma una categoría explicativa de algún proceso, y no un hecho fortuito de la trama social. Si bien ya se visibilizaban

\footnotetext{
2 Trabajo de campo con estudiantes de la Licenciatura en Historia, noviembre de 2016. Plaza Los Andes, barrio de Chacarita, CABA. En el santuario se puede ver no solo la imagen del Gauchito Gil sino también Jesús, y la Virgen de Luján. 
en la ciudad algunas expresiones de religiosidades no institucionalizadas singulares o marginales ${ }^{3}$ nunca sospeché la centralidad de la devoción al Gauchito Gil.

De esta manera, el territorio de la ciudad ejerce desde el poder simbólico de raíces neoculturales complejas -como rituales, mitos, creencias, milagros de matriz católica popular- el sentido de lo sagrado, en tiempos post-sociales. Fuimos viendo el camino lento pero continuo del Gauchito Gil -nacido en el siglo XIX- en Mercedes (Corrientes, Argentina) que llega finalmente a la ciudad de Buenos Aires. De esta manera de ser una práctica de marca espacial visible local en "los no lugares" de Marc Augé como rutas, luego autopistas, cruces de caminos, espacios de tránsito de las entradas a la ciudad, entre los principales sitios elegidos por los fieles hasta conquistar la visibilidad de sus santuarios en el área metropolitana. En los años noventa las imágenes de La Difunta Correa, San La Muerte y el Gauchito Gil convivieron en mundos plurales de religiosidad popular. No obstante, el Gauchito Gil fue colonizando el paisaje de los no lugares hasta dejar casi marginal o totalmente desplazadas a las otras devociones.

El Gauchito conforma una religiosidad popular no regulada, mágica y con matrices de devoción católica. En su creencia y fe se encarna lo masculino con la rebeldía y la búsqueda de justicia. Una presencia que reacciona frente al poder que oprime a los más vulnerables. A caso estamos en presencia de procesos urbanos neo culturales de fe. En esas primeras observaciones surgieron preguntas. ¿Por qué llega allí el santuario popular del Gauchito Gil? ¿Qué hace en una plaza su santuario y sus fieles, otrora lugar sagrado de lo público y secular?

Estos interrogantes me llevaron a retomar ideas de los años ochenta con la aparición visible de nuevos templos en los viejos cines de la calle Lavalle, a retomar ideas de fragmentación urbana sin precedentes. En este contexto, ¿que papel juega para nuestra ciudad post social en el encuentro con lo sagrado?

La ciudad como escenario privilegiado, marquesina y espacio sagrado me llevó a rememorar la obra de Racine (1993) La ville entre Dieu e les hommes. Para este autor, la ciudad será el fruto del contacto con lo sagrado. Posiciona a la ciudad en sus orígenes como la Casa de Dios, y puerta del Cielo, morada terrestre y espiritual de Dios. Es decir, que la noción del espacio ritual engendra lugares sagrados, y con ello, la idea de Ciudad Divina. El desarrollo de estos conceptos nos lleva de inmediato a preguntarnos ¿Cuáles son esos espacios sagrados en la ciudad contemporánea? Diría Racine, a partir de allí, la geografía se interroga.

\footnotetext{
${ }^{3}$ Sobre todo, en relación con las imágenes de San La Muerte en algunos barrios decriticidad social, desplazando las clásicas imágenes marianas. 
En nuestros territorios la espacialidad sagrada adquiere sus propios componentes y recomposiciones. Hemos recorrido ciudades en Latinoamérica donde el papel mariano ejerce un epicentro de religiosidad católica de la mano de la compleja trama social y cultural que nos caracteriza como sociedad. Por supuesto, se trata de culturas urbanas en continuas reinvenciones de prácticas sustentadas en mitos, memorias, narraciones de símbolos y linajes.

Para Racine (1993), como sociedades la ciudad ha sido búsqueda del contacto con lo sagrado, como la fuerza del lugar, y hará un completo análisis de las primeras siete civilizaciones de la humanidad para plantear al surgimiento de lo urbano como una relación entre Dios y el hombre, sin por ello, reducir su análisis o despreciar a los enfoques funcionalistas en lo que hacen a su explicación para las etapas posteriores de la difusión espacial de las ciudades, a través del tiempo. La ciudad es la expresión de la presencia soberana de los dioses entre los hombres, la residencia de los dioses que poseen allí su habitación bajo la forma de grandes santuarios, encontramos así varias afirmaciones de esta índole.

En el análisis de otras civilizaciones sintetiza que la presencia de lo divino está delimitada por el seno del lugar sagrado. Estos lugares sagrados eran toda la ciudad, en algunos casos, se reflejan claramente en la forma urbana, por ejemplo, con la construcción de Pekín en China. La arquitectura va adquiriendo, cada vez más, un papel protagónico, ¿no es acaso para moldear los espíritus? La respuesta es sí, ya que la ciudad moldea a sus sociedades y viceversa. No obstante, la ciudad como las sociedades es dinámica, y lo sagrado, lugar de sacrificios u homenajes a los dioses, dará lugar a los lugares cívicos por excelencia como el ágora y el forum. Es decir, cuando lo religioso y lo social están inmersos en una misma realidad. En el caso de nuestras civilizaciones precolombinas, las ciudades fueron el recinto del Inca y de lo sagrado. Las pirámides mayas 0 aztecas dan cuenta de la complejidad urbana y su vínculo con lo sobrenatural. Actualmente, en el marco de circulación de bienes de salvación se rescata o se recrean neo culturas o neo religiosidades que resignifican al espacio histórico de lo sagrado o lo renuevan con otros símbolos religiosos. Así, como en la antigüedad, la ciudad es la mediadora entre el Cielo y la Tierra; y como hoy, los espacios sagrados de la ciudad adquieren otras formas y contenidos sociales con un mismo propósito: encontrar un camino hacia lo divino y espiritual.

En plena ciudad postmoderna, los símbolos de lo religioso son resignificados en una sociedad híbrida y secularizada, con la fuerte impronta del campo católico. Buenos Aires, ciudad secular, modelo a seguir frente a la idea de modernidad es atravesada por otras fuerzas de lo neosagrado: la devoción del Gauchito Gil. Devoción que impone su propia marca, su neocultura urbana con raíces en el mundo rural argentino, hoy presente entre nosotros por sus milagros. 


\section{8:}

El Gauchito Gil llega a una Buenos Aires de matriz urbana de rupturas sociales y de retracción del Estado de Bienestar, frente al desconcierto de las desregulaciones y de la exclusión sin precedentes. Cabe aclarar, la cultura y religiosidad del Gauchito Gil va más allá de los pobres o excluidos, hoy sus devotos no conocen fronteras.

En otras palabras, la modernidad desde su racionalidad instrumental ocasionó una particular matriz de organización social como la postmodernidad, aunque actúan por diferentes circuitos o mecanismos. Ambos procesos políticos se han esmerado en divorciar al símbolo religioso de su contenido trascendente, han intentado desplazarlo, neutralizarlo o universalizar sus significados culturales. En tan solo casi veinte años he podido ser testigo -en el contexto latinoamericano- del esfuerzo intelectual, y en especial desde la Geografía, por ofrecer herramientas teóricas para acompañar las mutaciones sociales, políticas y culturales que hacen de la religión nuevas expresiones territoriales de religiosidad reinventadas, reconstruidas, re apropiadas por diversas tradiciones o prácticas tanto individuales como grupales. Todos hacia una búsqueda incansable de diversa magnitud y complejidades que permiten atravesar nuevas significaciones simbólicas y de experiencias sagradas, sostenidas por nuevos marcos de creencias.

No obstante, el vaciamiento de tradiciones y simbolismos religiosos nos han dejado huérfanos de creencias y rituales que sostenían aspectos difíciles de la vida como la enfermedad, la muerte, por ejemplo, hoy resumidos a la negación del dolor o al trámite ágil de una despedida trascendental. Por otro lado, las formas de acumulación del capital a cualquier precio ambiental y social, nos ha dejado una sociedad fragmentada y ciudades críticas por la pobreza y la violencia. Nos han desmantelado los circuitos y cadenas sociales que otrora permitían lazos de solidaridad colectiva. Las migraciones forzadas, la exclusión fueron acompañadas por culturas y religiosidades como trasmisoras de esperanza y proyección social.

En este mundo global hay mundos locales. Hay lazos que se reconstruyen y el lugar pasa a ser la esperanza a la vez que resistencia frente a esta máquina invisible y visible que arrasa con lo conocido. Estos procesos, mutan y recrean territorios alternativos de fe. Refugios que construyen individual y colectivamente nuevas relaciones y mutaciones culturales de religiosidad popular. Además, en nuestras tramas sociales contemporáneas, no podemos dejar de lado la influencia que tienen las tecnologías de la información que nos reconstruyen y propician nuevas formas espaciales de organización social como espiritual. Lo que Marc Augé denomina "sobremodernidad" (1995) en contextos de globalización, la que caracteriza entre otros aspectos el achicamiento de las distancias en la mundialización al mismo tiempo que se expresa como 


\section{9:}

nunca la sobreindividualización de la cultura. En este sentido la sobreindividualización ${ }^{4}$ nos desborda hacia una matriz de religiosidad popular que adquiere componentes sociales híbridos.

Por otra parte, la presencia urbana del Gauchito rompe con la idea simple de la complementariedad y contradicción, a través del tiempo, entre civilización y barbarie, como un juego intrínseco del dilema urbano. ¿A qué idea se asociará lo religioso ligado a la idea de ciudad? Por ello, es esencial interrogarse sobre la relación que la ciudad mantiene con lo religioso del cual lo sagrado es la esencia de nuestra interacción con los símbolos territoriales y creencias. Es entonces donde podemos afirmar la idea de Racine de que la ciudad es la imagen del hombre y de la sociedad. Cuerpo viviente a su imagen, la ciudad está hecha tanto de ideas y de cultura como de piedras y de habitantes.

Para ir cerrando, podemos decir que han persistido en todos los tiempos una estrecha relación entre lo sagrado, el mito, la utopía como fuerzas organizadoras del espacio urbano. En este sentido el paisaje de la ciudad nos lleva a una interpretación para nada reduccionista del actual urbanismo y de las prácticas religiosas que intentan superar la exclusión e inequidad. Estado y sociedad postsocial terminan por desplazar las conocidas tradiciones religiosas por nuevas estrategias de supervivencia individualizadas o colectivas. El Estado y el régimen político, en contexto de modernidad y postmodernidad, cambian a la sociedad y a la ciudad. Se trata de una mayor separación Estado-sociedad, ampliación de la sociedad civil, pluralización e individuación, pero, a la vez, fragmentación y exclusión. El desplazamiento del Estado por el mercado como ámbito privilegiado de las iniciativas sociales implica también un desplazamiento en los principios de legitimación y organización social del territorio. Como dice Guillermo O'Donnell (1993) es un error asociar al Estado únicamente con el aparato estatal o el sector público. El Estado es también, y no menos primariamente, un conjunto de relaciones sociales que establece cierto orden en un territorio determinado, y finalmente lo respalda con una garantía coercitiva centralizada.

\section{En búsqueda del Gauchito Gil: narraciones de adaptaciones culturales ${ }^{5}$}

La amplitud es central: a un santo cristiano sólo se le pueden pedir acciones respetables. Al Gauchito, en principio, cualquier cosa. Aunque, últimamente, estén tratando de civilizarlo. El Gauchito Gil tiene el pelo negro y largo, camisa azul, su pañuelito rojo al cuello. El rojo es su color:

\footnotetext{
${ }^{4}$ En este sentido Reneé De la Torre (2006) analiza las recomposiciones de prácticas mágicas, el new age, y otras que actualizan sus formas de rituales y creencias frente a una nueva sociedad global y sus reinvenciones en Guadalajara.

5 Trabajo de campo con los estudiantes de la Licenciatura de Historia de la Universidad Nacional de Avellaneda, segundo cuatrimestre 2016.
} 
el rojo puede ser la sangre derramada y puede ser, también, la enseña federal que llevó al Interior a la derrota. Antonio Gil es el Interior hecho creencia. Antonio Gil es la gauchesca hecha superstición (CAPARRÓS, 2006, p.12). ${ }^{6}$

Podemos coincidir, para dar inicio a esta reconstrucción, que las narrativas son constitutivas del espacio sagrado como la fuerza del lugar que traen consigo un paisaje histórico como mítico, pasado y presente. Es un trayecto sin concluir que solo puede tener lugar en los imaginarios y creencias personales del milagro. Así las ideas que circulan nos proporcionan un acerbo y contexto simbólico que se posiciona sobre un relato histórico con voces anónimas. Retomo las ideas de Cerezo (2018) Todo territorio es una proyección de los imaginarios sobre el lugar. El espacio es pensado en términos de asociaciones con lo conocido, por semejanza o por oposición. Entonces el territorio expandido es un territorio construido en una movilidad incorporada por los fieles y la imaginación de un territorio.

Frente a la movilidad espacial de creencias y a la sociedad de consumo - exclusión, nuestras comunidades fueron coevolucionando ese mundo cultural invisible de los seres sobrenaturales. Las leyendas o mitos abundan en todo el interior del país. E inclusive con imaginarios traídos en las diferentes oleadas migratorias. Todo se fusiona en nuevos territorios de religiosidad, territorios alternativos de fe. Quizás, la causa fundamental de la difusión del Gauchito radique no solo en su creencia y estrategia popular de marcar territorios de una profusa inventiva colectiva. Hay algo más, detrás del imaginario hay realidades parciales seleccionadas y mutadas por sus propios proyectos de salvación. Esta supervivencia radica en la propia esencia de la existencia de la mayor parte de esas manifestaciones, ya que permanecen vivas desde el nivel testimonial. La figura del Gauchito Gil emanó de la inventiva de las gentes que se sitúan en una época histórica de luchas intestinas en Argentina, fusionando los elementos del tiempo histórico con los imaginarios o creencias.

En esta parte del trabajo se da cuenta del momento histórico donde se desarrolla la vida y muerte del Gauchito Gil, incluyendo también, algunas voces que trasmiten su legado.

Se considera una pieza fundamental en el análisis del presente retomar estos acontecimientos del tiempo histórico específicos que enmarcan las raíces y explica, en parte, la extensión de esta religiosidad popular en todo el país. Si nos remitimos a las raíces del Gauchito Gil, nos encontraremos con varias versiones que dan a conocer su "historia". Entre estos relatos, se coincide en que nace cerca de Mercedes, en la provincia de Corrientes, alrededor de 1840 con

\footnotetext{
${ }^{6}$ Selección extraída de la nota "Las devociones populares en la literatura (3): El santuario del Gauchito Gil en Mercedes por Martín Caparros, realizada por Alejandro Frigerio, Página 12, 2013. 
el nombre de Antonio Gil Nuñez. Por ese entonces Rosas ya estaba a cargo de su segundo gobierno y contaba con las famosas facultades excepcionales. No está de más mencionar que la sociedad de ese entonces estaba inmersa en un duro enfrentamiento entre unitarios y federales. En ese tiempo de fragmentación política y civil, Rosas es el encargado de "restaurar el orden" con estrategias populares sumando a los sectores rurales, olvidados por su barbarie. Como dice John Lynch

“...Rosas se identificó así culturalmente con el gaucho. Educó a su hijo en la misma forma. El general Gelly relataba una anécdota sobre una visita que hizo Rosas a la estancia de su madre, acompañado por dos asistentes y su joven hijo Juan. Rosas dejó al muchacho en la cocina y rehusó el pedido de su anfitrión para que lo llevara a la mesa de la familia, diciendo: Déjenlo, compadre, que se quede con los soldados y almuerce en la cocina con los peones..." (LYNCH, 1984, p.109).

Es así como Tulio Halperín dice: "la politización de las masas rurales y la movilización popular contra los unitarios en 1829 convencieron a Rosas de que el Río de la Plata sólo podía ser gobernado popularmente..." (1972: 301). A través de diferentes autores se puede afirmar el liderazgo político y cultural de Rosas, su fuerte influencia a favor del gaucho fue la clave de su éxito. Esta política rosista atrajo a muchas voluntades de la sociedad rural marginada. En este escenario se identifica la imagen de Antonio Gil. Identidad federal, cuya vestimenta es un componente de su imagen.

Sus primeros años de vida se enmarcan bajo el mandato del unitario Pedro Ferré, quien gobernaba la provincia de Corrientes. Esta provincia estuvo dirigida por Juan Lavalle. El destino de estos dos personajes no fue muy grato puesto que Ferré pierde la vida en la Batalla de Famaillá ocurrida el 19 de setiembre de $1841^{7}$ y para fines de ese mismo año Lavalle había muerto. Estos acontecimientos fueron formando la posición política de Gil, acompañados por actos de humildad. Luego de la caída de Rosas, se instalan en Argentina las políticas liberales, fijando las bases para la formación del Estado-Nación. Oszlak dice al respecto:

\footnotetext{
"el surgimiento del Estado nacional es el resultado de un proceso de lucha por la redefinición del marco institucional considerado apropiado para el desenvolvimiento de la vida social organizada. Esto implica que el Estado nacional surge en relación con una sociedad civil que tampoco ha adquirido el carácter de sociedad nacional. Este carácter es el resultado de un proceso de mutuas determinaciones entre ambas esferas..." (OSZLAK, 2012, p. 17).
}

\footnotetext{
7 La Batalla de Famaillá o Batalla del Monte Grande (provincia de Tucumán, Argentina) terminó con la victoria del ejército federal argentino, al mando del uruguayo Manuel Oribe. 


\section{2:}

Estos procesos de orden social recorren a toda América Latina dejando las bases de un desarrollo capitalista por vía oligárquica, luego de las guerras civiles y el corrimiento del indígena, haciendo posible el avance económico basado en un estado autoritario. Finalizada la batalla de Pavón (1861) el partido liberal se impone por todo el territorio, a través de alianzas o por invasiones militares. Todos los gobernadores, menos uno, eran liberales aliados de Mitre. En la provincia de Corrientes todavía hay cierta resistencia al liberalismo, pero finalmente se impone el modelo de Nación.

Figura 2 - El Gauchito8.

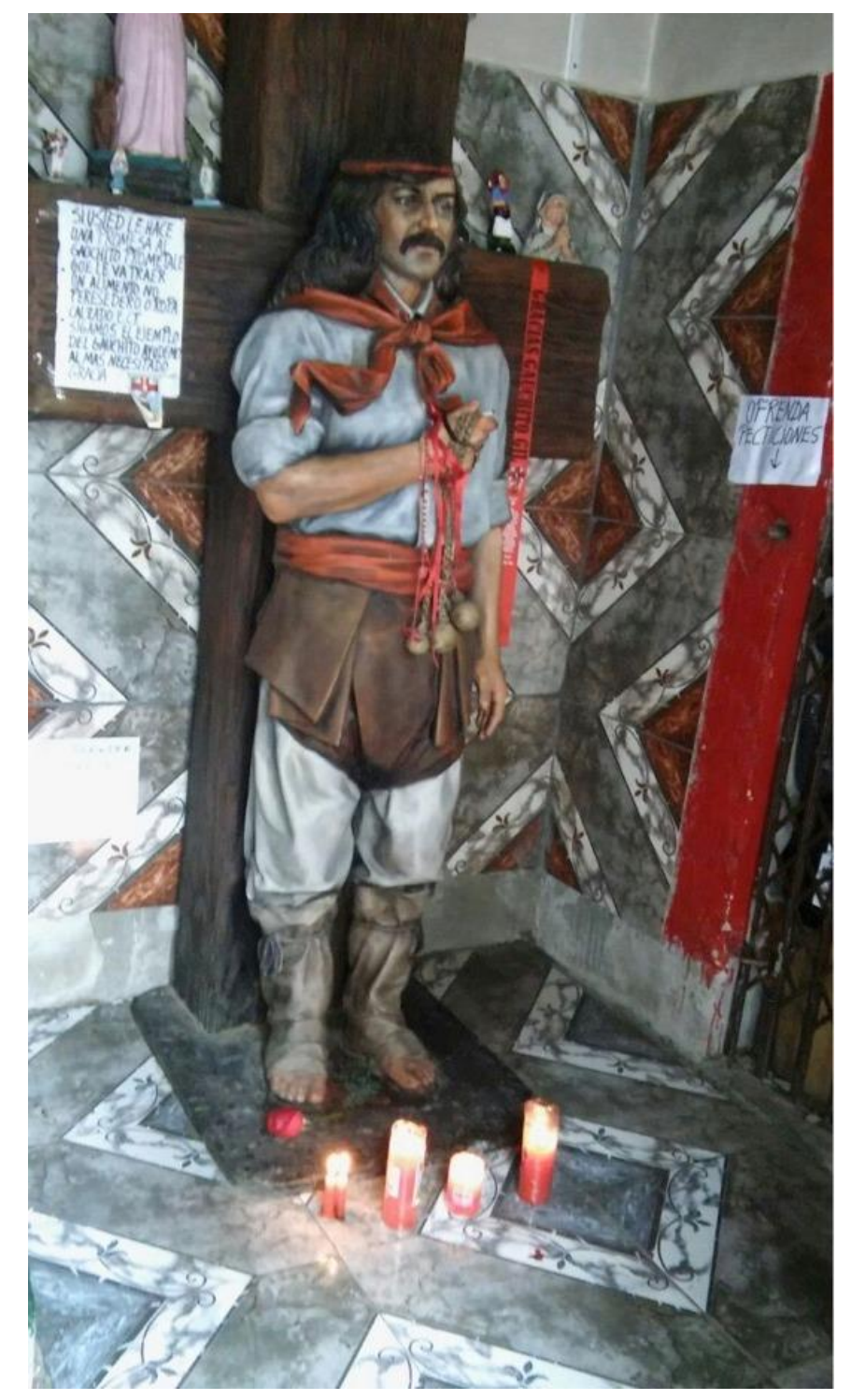

Fuente: Carballo, 2016.

\footnotetext{
${ }^{8}$ Trabajo de campo con estudiantes de la Licenciatura en Historia, noviembre de 2016. La vestimenta recrea al gaucho federal y el rojo se expande en todas las celebraciones.
} 
En el presente se recrea diferentes voces con ciertas coincidencias por ejemplo el tiempo se desarrolla la vida y muerte de Antonio Gil. En los relatos se destaca que fue un hombre de campo dedicado a las tareas agrícolas. Era fiel creyente de San la Muerte y por su posición política se puede dar cuenta de que además intervino en las luchas internas de Corrientes, y luchó contra el poder opresor. Siendo apenas un hombre de poca edad participó en la guerra de la Triple Alianza, donde Argentina, Brasil y Uruguay invaden Paraguay dejándola completamente devastada. Al respecto dice José Luis Romero:

[...] la Argentina, el Uruguay y el Brasil combatieron contra el mariscal Francisco Solano López desde 1865 hasta 1870 y lo derrotaron en una contienda que en la Argentina declaró que la victoria no da derechos. Por lo demás, sus intereses se volvían cada vez más decididamente hacia Europa, donde las transformaciones técnicas y sociales estaban creando nuevas y promisorias oportunidades para los productores argentinos [...] (ROMERO, 1996, p.102).

Durante el transcurso de la guerra, Gil, cae en desgracia con las autoridades, es apresado y asesinado por un emisario que envía el coronel. Según cuentan los testimonios, este gaucho, es apresado por desertor de la guerra contra el Paraguay.

Julio, quien llevó a cabo la construcción de unos de los principales santuarios del conurbano, dice:

[...] era un soldado en la época de la guerra de la triple alianza, fue enrolado para participar en la guerra y una noche tiene una visión por medio de un sueño en donde Dios le dice: ¿Por qué vas a derramar sangre de gente inocente? A través de esta visión, decide huir junto con unos compañeros. Los desertores son perseguidos para ser ejecutados, pero mientras están prófugos Gil y sus compañeros cazan animales para subsistir y compartir con la gente pobre del lugar. Tras días de persecución finalmente es capturado y colgado de un árbol donde es degollado, pero antes sus últimas palabras, hacia quien lo última son las siguientes: cuando llegues a tu casa tu hijo estará enfermo de muerte, recordáme, rezá y pedí en mi nombre que se salve... cuando el indio llega a su rancho efectivamente esto sucede por lo que éste de inmediato hace lo que Antonio Gil le había dicho, salvando la vida de su hijo $[\ldots]^{9}$.

Desde este hecho milagroso, sobrenatural, se inmortaliza y materializa la imagen del Gauchito Gil. El gaucho responde a una estructura relacionada con la condición de paisano humilde que finalizan teniendo problemas con la autoridad, huyendo y muriendo trágicamente tras una emboscada. Los relatos sobre el Gauchito Gil plantean en cierta forma una coexistencia del sujeto histórico, aunque los hechos no parecen confirmarlo. El interés sobre él no reside en esta divergencia, sino en priorizar el objeto cultural que constituye; en señalar sus valores simbólicos y en revelar la capacidad de la imagen como lenguaje y canal de expresión.

\footnotetext{
9 Entrevista a Julio, Bernal, 08/10/16. 
Si bien no hay registros históricos de estos hechos, el nacimiento del mito, hizo que se le otorgue carácter sagrado al paraje donde ocurre su muerte según surgen de las fuentes orales. Hoy el lugar es visitado por cientos de devotos. En relación a estos procesos Sousa (2013:158) nos dice: "La veracidad del mito no necesita de la existencia material del personaje y más allá de las dudas sobre el sujeto histórico cuyos datos no responden a lo que aporta la documentación de la época, es una construcción simbólica argentina". Desde la década del '90, junto con la llegada y el desarrollo del neoliberalismo, comenzó a pronunciarse cada vez más la cantidad de devotos del Gauchito, ¿coincidencia? O acaso podemos recuperar la idea de resistencia social como en otros tiempos de opresión y persecución. Tal vez por el hecho de que la gente necesita creer en algo y pedir milagros que resuelvan sus necesidades más urgentes pueda contextualizar las devociones, con connotaciones de malestar y repudio a la opresión. Lo curioso es que estos lugares concebidos por la imaginación en definición encuentran la necesidad de expresar en el territorio su santuario. Estos lugares de sacralidad no son casualidad ni tampoco pasan desapercibidos, siendo estos lugares epicentros de religiosidad popular.

[...] lo que asumimos como religiosidad popular, lo que nos lleva a cuestionar una realidad naturalizada de los paisajes de devoción religiosa e identificar a grupos sociales que conviven construyendo espacios a través de la memoria. Prácticas que ponen en discusión la universalidad del concepto de religiosidad popular [...] (CARBALLO, 2012, p.81).

\section{Mecanismos simbólicos del paisaje como refugios de religiosidad: los altares del Gauchito}

"[...] se trata de una figura cuyo reconocimiento es producto, exclusivamente, de la decisión del pueblo. No se trata de una imagen cuya veneración haya sido establecida institucionalmente por organizaciones o personas vinculadas al poder [...]" (AMEIGEIRAS, 2008, p.83). 
Figura 3 - Dev Bernal10

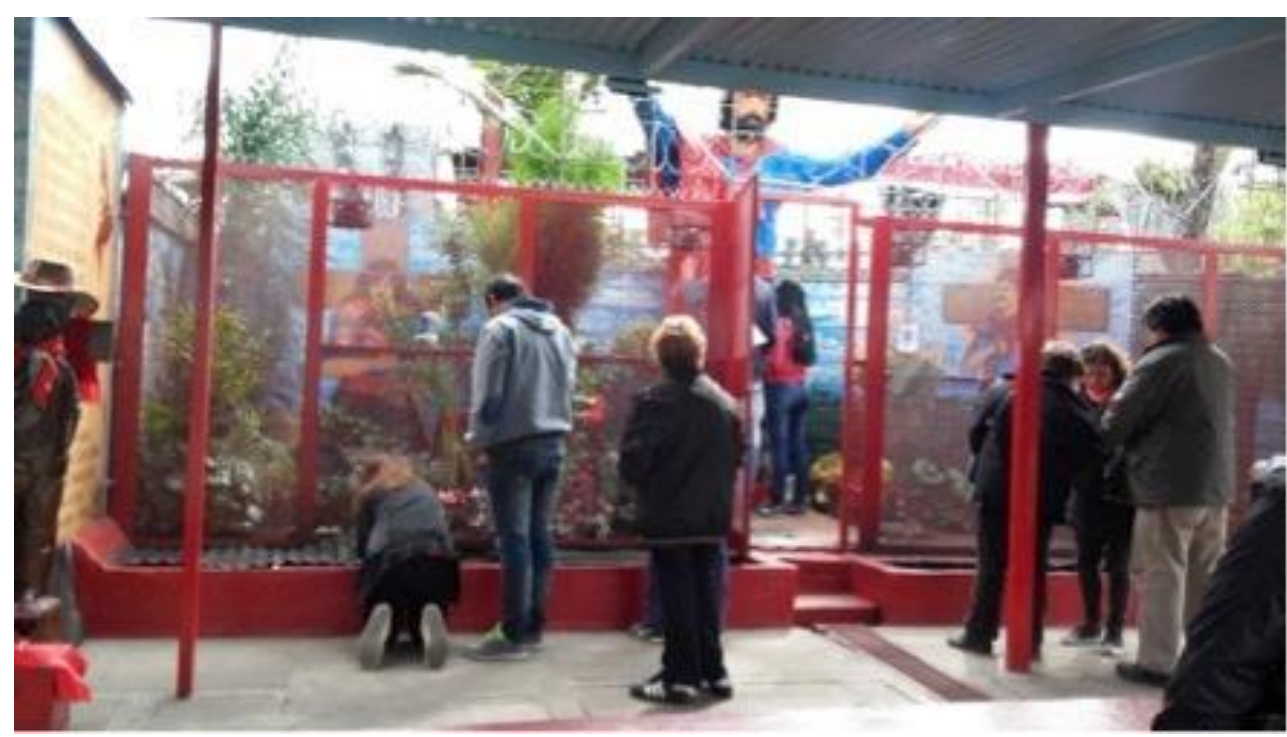

Fuente: Carballo, 2016.

El rojo inunda la escena, lo que es una pila de botellas en el primer caso, lo reemplazan montones de cintas y banderas rojas, estatuillas, placas de agradecimientos, flores que dan y color de sacralidad popular al lugar. En este sentido se considera que

a través de símbolos y legitimaciones sociales que conducen a una reconstrucción continua del catolicismo popular, del que no escapan los peregrinos gauchos. Es por ello que a raíz de estas expresiones históricas, sociales y políticas dan como resultado una cultura y religiosidad popular, en la que se entiende que la fe de los simples, religiosidad imbricada en la cultura son expresados con signos sensibles en que, muchas veces, se practican al margen del cuerpo eclesiástico. Podremos plantear entonces que la principal distinción de lo que es catolicismo popular del que no lo es, es considerar las otras formas que asume la religiosidad en distintos contextos y su dinámica, más allá de lo estrictamente eclesial e institucionalmente legitimado, es decir, la práctica social y cultural de la religiosidad católica o "a modo católico". De esta forma, deberíamos tener en cuenta para la comprensión las sub-identidades católicas a la religiosidad popular (CARBALLO, 2016, p. 85).

Si bien la Iglesia Católica no reconoce al Gauchito como santo ni beato en general, la Iglesia local desde hace algunos años empezó a celebrar misa en el santuario de Chacarita, lo que nos da una idea de la magnitud del fenómeno popular y de su forma a modo católico. Es decir, no solo en la utilización de las imágenes sino también en las formas de comunicación con el santo, como podemos ver en la práctica de la novena al Gauchito Gil.

10 Trabajo de campo con estudiantes de la Licenciatura en Historia, noviembre de 2016. Intersección entre la ciudad de Avellaneda y Quilmes. En el santuario aparecen ofrendas y rezos de los promeseros. 
La figura del Gauchito Gil hoy dejó de ser la de un gaucho correntino más, no importa si vivió fuera de la ley. Gil es un justiciero local, un patriota que se negó a derramar sangre de hermanos, un héroe, o un mártir, como dice Mauro Daniel Salvador:

pasó a formar parte de un lenguaje popular de adoración, agradecimiento, plegaria y peregrinación. A ser parte de la cultura religiosa popular con matriz criolla, mestiza, gauchesca, federal y conformando nuevos sentidos y pertenencias de identidad nacional. Por todo lo mencionado cada vez que se lea, vea u oiga sobre la figura del Gauchito Gil en las distintas formas y expresiones, en las distintas formas y expresiones, se estará ante la presencia de la religiosidad popular argentina, en qué se cree y cómo; ante la capacidad para reformular y seguir abarcando signos y significados, en este caso puntual desde un discurso que reconfigura el mito, la adoración y la fe (SALVADOR, 2016, p. 439).

Es por ello que el sentir del devoto del Gauchito no se limita a la búsqueda de ayuda, sanación, no es solo un milagrero, simboliza el hombre común, con sus virtudes y defectos, hoy héroe, hoy santo, pero también vengativo, al que hay que cumplirle las promesas, o no será beneficiado con nuevos favores, y hay que agradecerle con velas, cigarrillos, vino, comida, baile, chamamé, conformando así un ambiente de fiesta popular. Por eso es el santo argentino, y por eso es gaucho. La religión popular es una posibilidad concreta de autoafirmación y resguardo, un recurso de carácter mítico-simbólico unido a un bagaje experiencial y vinculado con el universo cultural en el que los sujetos de los sectores populares despliegan su existencia (AMEGEIRAS, 2008).

El santuario de Mercedes, lugar de la muerte, es precario comparado con la difusión que tiene la devoción. "Un santuario con estructura de villa del tercer cordón de Buenos Aires: hay problemas de jurisdicción, de propiedades, que hacen que no se pueda construir nada permanente."11 No obstante, los geosímbolos de ese paisaje intentan replicarse en los santuarios o ermitas, uno de ellos es el árbol. El árbol en la historia del Gauchito Gil, es una pieza central de la tragedia. Un 8 de enero de 1878, en tiempos del mandato de Avellaneda, los soldados lo ataron de los pies y lo colgaron cabeza abajo del algarrobo que todavía está allí en Mercedes. Estaban por matarlo y le dijeron que lo iban a dejar tirado ahí, para los caranchos. Antonio Gil dice: "Si no me enterrás, cuando vuelvas a tu casa te vas a encontrar a tu hijo muy enfermo, pero si mi sangre llega a Dios, juro que volveré en favores para mi pueblo"12

El caso de la ciudad de Rosario, analizado por Alejandra Belinky (2008), nos permite recuperar varias afirmaciones de su trabajo. En particular, el santuario se inicia con la colocación

11 Selección extraída de la nota "Las devociones populares en la literatura (3): El santuario del Gauchito Gil en Mercedes por Martín Caparros, realizada por Alejandro Frigerio, Página 12, 2013.

12 Ibidem. 
de una cruz proveniente de Mercedes, a la que le atribuyen un carácter no sólo sagrado, sino también sacralizante por su origen. Afirman que al apoyar un rosario, una vela o una estampa sobre la misma estos objetos estarían bendecidos sin necesidad de la intervención de un sacerdote. $Y$ allí se produce el lugar sagrado con la invocación a Gil reconstruyendo un paisaje rural mítico atemporal. Este paisaje logra transportar el ser "gaucho" y correntino, acercando el campo a la ciudad. Para la autora, este santuario simboliza una sacralidad gaucha que contiene dos dimensiones a rescatar como sublevación popular: 1) Rompe con la ciudad normatizada, 2) Rompe con la regulación / mediación de los cultos tradicionales.

La creación de estos santuarios populares por fuera de la institucionalidad implica dar formato de sacralidad a determinados sitios de la ciudad. Muchos de ellos de formas tan precarias como los escenarios urbanos. Estas colonizaciones de religiosidad en los espacios públicos, que los sujetos individuales y colectivos hacen, cuando construyen un altar, no sólo inscriben huellas sobre el espacio, sino que también disputan un nuevo lugar de reconocimiento ciudadano. Esta apropiación del espacio como en el caso de la Plaza los Andes, lo convierte en un espacio de sacralización dentro de un sitio planificado, como es una plaza pública, y que le otorga así, otro sentido a ese espacio. Las formas simbólicas que van desde lo religioso a lo mágico y viceversa, forman un campo donde se articulan las imágenes, las ideas, las creencias, las necesidades y las acciones. "Una de las funciones de los imaginarios sociales consiste en la organización del tiempo colectivo y el dominio del sobre el plano simbólico [...] Toda ciudad es una proyección de los imaginarios sociales sobre el espacio..." (BACKZO, 1990:30)

Se imponen nuevas formas de imaginación y por lo tanto de expresión religiosa, en el espacio urbano. Lo que evidencia es que si bien ciertas formas de devoción religiosa han desaparecido, en el presente observamos formas más conscientes, voluntarias y activas de participación religiosa en los medios urbanos, irrumpiendo con paisajes de neoculturas urbanas en búsqueda de un refugio espiritual.

\section{Reflexiones sobre neoculturasurbanas: entre símbolos de sueños y esperanzas}

\footnotetext{
"A partir de ese origen, toda creencia evoluciona y se retroalimenta con nuevos significantes que van camuflando el significado esencial que marcó su desarrollo con el objetivo de adaptarlo a las necesidades simbólicas imperantes en la comunidad que lo sostiene. De este modo, las creencias siempre están actualizadas. De lo contrario, carecerían de sentido y caerían en el olvido" (FRENAN CAMPO, 2017, p.13)
} 
Podríamos sintetizar algunos elementos que se desarrollaron en esta reflexión de los espacios sagrados en la ciudad. Estos santuarios son agenciados por una comunidad que no necesita de una legitimación institucional religiosa o pública. La comunidad lo hizo santo. Una comunidad de anclajes locales que se recompone en el lugar. Lugar mágico para fieles que buscan alguna forma de salvación material y espiritual. Imaginarios de aquello que es sobrenatural y divino con proyecciones y adaptaciones territoriales. Es decir, la religión como refugio y algo más. En este sentido se rescatan algunas ideas fuerza sobre la práctica urbana: 1) Rompe con la ciudad de la modernidad o excluyente de la postmodernidad. 2) Expresa territorialidades de sobreindividualización religiosa bajo formas de imaginarios colectivos de salvación. 3) Expresa visiblemente otro tipo de vinculación con lo sobrenatural y con la regulación y mediación de los cultos tradicionales. 4) Reduce los impactos negativos de la ciudad postsocial con lazos sagrados y búsqueda de esperanza. 5) Genera neosimbolismos y recrea significados que provienen del mundo rural olvidado. 6) La fuerza del lugar sagrado, no solo reside en Mercedes, sino en el lugar que conlleva su significado, adquiriendo improntas de cada imaginario local. 7) Las matrices católicas de su culto perviven con la invención popular desregularizada y creativa, como una dimensión cultural arraigada en lo que concierne a formas de adoración y veneración.

La territorialidad sagrada del Gauchito Gil es opuesta a un espacio sin marcas, por el contrario, necesita del color de su imagen y del paisaje mítico correntino que promueve significados sobreindividualizados a la vez que solidarios. La leyenda o el mito de su muerte, el porqué de su persecución, su nobleza y rebeldía, y su palabra y milagro, son elementos que unifican las trayectorias personales y dan cohesión colectiva. El paisaje del culto no pasa desapercibido a la sociedad que comprende superficialmente lo que se comparte como culto detrás de las filas y ofrendas. Allí en su espacio sagrado se expresa la necesidad material y espiritual. Esta constituye una comunidad de fieles nómadas, ya que algunos comparten otras creencia y prácticas católicas o evangélicas, que se encuentran y solidarizan su forma de creer en determinados anclajes simbólicos, y el paisaje neocultural toma forma.

El territorio del santuario no solo es indispensable para su existencia sino como símbolo sagrado, esto es justamente lo hace del lugar algo divino y sobrenatural. En otras palabras, los devotos construyen su lugar en la ciudad y se pueden reconocer ellos mismos como una comunidad de fieles que se reivindica en el espacio público (SEGATO, 2008) como sagrado y festivo. En palabras de Racine (1993) la ciudad sigue actuando como el escenario de contacto entre lo humano y lo Divino. 
En ese altar elemental desde la mirada urbana se replica una simplicidad en el mundo del trabajo rural. Sincretismos de una ermita que contiene al Gauchito Gil, pero también a San La Muerte junto con la Virgen de Luján. Es decir, la dimensión del territorio adquiere expresiones no solo en el paisaje imaginado, no solo en las marcas de una plaza o esquina de la ciudad sino también en los cuerpos como portadores de manifestaciones sagradas, en sus ropas, en la música, en los símbolos que llevan en sus autos, en sus casas, en los rosarios, en las novenas. En síntesis, el territorio es la convivencia y coexistencia de todas esas formas, es portador de contenidos y de significantes complejos. Estos procesos hacen del culto al Gauchito Gil una neocultura urbana de religiosidad popular.

Los mecanismos simbólicos de sacralidad popular nos ayudan a encontrar las respuestas que el mundo actual, racional, mercantil y científico nos niega.

\section{Referencias}

AMEIGEIRAS, A. Religiosidad popular: creencias religiosas populares en la sociedad argentina. Buenos Aires: Universidad Nacional de General Sarmiento, 2008.

BACKZO, B. Los imaginarios sociales. Memorias y Esperanzas Colectivas. Buenos Aires: Nueva Visión. 2da. Ed, 1990.

BELINKY, A. Devoción al Gauchito Gil en Ciudad de Rosario y Gran Rosario. Un Análisis de los Aportes desde los Estudios Cuantitativos a una Perspectiva Cualitativa. Nuevos Problemas, Nuevos Desafíos in: Sociedad y Religión: Sociología, Antropología e Historia de la Religión en el Cono Sur, vol. XX, núm. 32-33, 220-241, 2010.

CARBALLO, C. Repensar el territorio de la expresión religiosa in: CARBALLO C. (coord.), Cultura, territorios y prácticas religiosas. Buenos Aires: Prometeo, 2009.

CARBALLO, C. Caminos del peregrino gaucho memoria y voces de la tradición religiosa en el catolicismo argentino in: Espaço e Cultura, Revista 31, janeiro-junho. 80-93, 2012.

CARBALLO, C. Paisaje y naturaleza del mundo rural pampeano: cartografías de patrimonio cultural. Presentación en realizada en el $1^{\circ}$ Colóquio do Observatório de Paisagens Patrimoniais e Artes Latino Americanas [OPPALA], Fortaleza, 26 de febrero de 2018. Organizado por UEC, UFCE y UFRN.

CEREZO, G. Marcas religiosas, territorios y espacios en el culto al Gauchito Gil" in: CARBALLO, $C$ \& FLORES, F. (Compiladores) Geografías de lo sagrado en la contemporaneidad. Serie Encuentros, Departamento de Ciencias Sociales. Buenos Aires: Editorial de la Universidad Nacional de Quilmes, pp.305-319. En prensa, 2018.

DE LA TORRE, R. Circuitos mass mediáticos de la oferta neoesotérica: new age y neomagia popular en Guadalajara in: Alteridades, 16 (32), 29-41, 2006. 
GARCIA CANCLINI, N. Definiciones en transición in: MATO, Daniel Cultura, política y sociedad Perspectivas latinoamericanas. Buenos Aires: CLACSO, Consejo Latinoamericano de Ciencias Sociales, pp. 69-81, 2005.

HIDALGO PEREZ, E. La aparición de un nuevo ser sobrenatural: la mora hispana in: Revista ArtyHum No 6, 5-14, 2014.

FRENAN CAMPO, A. Morir en el siglo XXI: cuando lo simbólico se hace imprescindible in: Revista ArtyHum No 38, 8-23, 2017.

FRIGERIO, A. Las devociones populares en la literatura (3): El santuario del Gauchito Gil en Mercedes por Martín Caparros in: Página 12, 5 de octubre de 2013.

LYNCH, J. Juan Manuel de Rosas. Buenos Aires: Emecé Editores, S.A., 1984.

O’DONNELL, G. Acerca del Estado, la democratización y algunos problemas conceptuales. Una perspectiva latinoamericana con Referencias a países poscomunistas. http://www.catedras.fsoc.uba.ar/deluca/odonnell.pdf. Consulta 4-10-2018, 1993.

OSZLAK, O. La formación del Estado argentino. Orden, progreso y organización nacional. Buenos Aires: Ariel, 2012.

RACINE, J-B La ville entre Dieu et les hommes. Paris: Presses Bibliques Universitaires et Anthropos, 1993

ROMERO, J. L. Breve historia de la argentina. Buenos Aires: Ed Tierra Firme, 2007

SALVADOR, M. Gauchito Gil, entre la adoración y la justicia divina. Un acercamiento al mito religioso popular desde la comunicación in: Questión. Revista especializada en periodismo y comunicación. Vol. 1, Núm. 50, 428-440, 2016.

SOUSA, I. Antonio Gil: historia de un gaucho imaginario in: Ecléctica, Revista de estudios culturales. núm. 2, 150-159, 2013.

SEGATO, R. La faccionalización de la república y el paisaje religioso como índice de una nueva territorialidad in: ALONSO, Aurelio (comp.) América Latina y el Caribe: Territorios religiosos y desafíos para el diálogo. Buenos Aires: Clacso, pp. 41-81, 2008. 